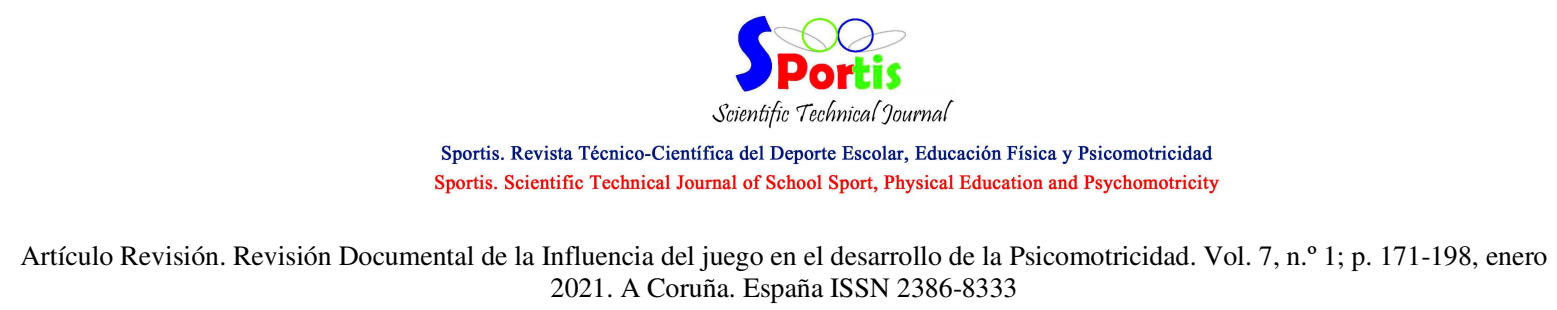
2021. A Coruña. España ISSN 2386-8333

\title{
Revisión Documental de la Influencia del juego en el desarrollo de la Psicomotricidad
}

\section{Documentary Review of the Influence of Play on the Development of Psychomotority}

\author{
Jayson Andrey Bernate \\ Corporación Universitaria Minuto de Dios UNIMINUTO
}

Contacto: jbernate1@uniminuto.edu.co

Cronograma editorial: Artículo recibido: 03/07/2020 Aceptado: 07/10/2020 Publicado: 01/01/2021
https://doi.org/10.17979/sportis.2021.7.1.6758

\begin{abstract}
Resumen
El juego es un aspecto imprescindible en la vida, sobre todo en las edades infantiles, más aún cuando se gestan los primeros eslabones del desarrollo motriz del ser humano. El objetivo de este artículo es realizar una revisión documental-sistemática donde se evidencie la vinculación del juego al desarrollo de la psicomotricidad. La metodología utilizada fue la revisión documental sistémica, por medio de protocolos de búsqueda y fases heurísticas. Los resultados arrojan que la mayor parte de estudios realizados son en la etapa inicial de la educación, siendo el juego un factor que se constituye como herramienta necesaria e imprescindible para el desarrollo de la psicomotricidad infantil. A modo de conclusión se parametriza el juego como un elemento primordial en el progreso de las capacidades motrices y en el crecimiento biológico y psicológico de los niños, además de aportar en el quehacer pedagógico de los docentes y darle el valor necesario a los aprendizajes lúdicos y corporales de manera mancomunada.
\end{abstract}

\section{Palabras clave}

Juego; Psicomotricidad; Aprendizaje Motor; Revisión Documental.

Para citar este artículo utilice la siguiente referencia: Andrey Bernate, J. (2021). Revisión Documental de la Influencia del juego en el desarrollo de la Psicomotricidad. Sportis Sci J, 7 (1), 171-198. https://doi.org/10.17979/sportis.2021.7.1.6758 


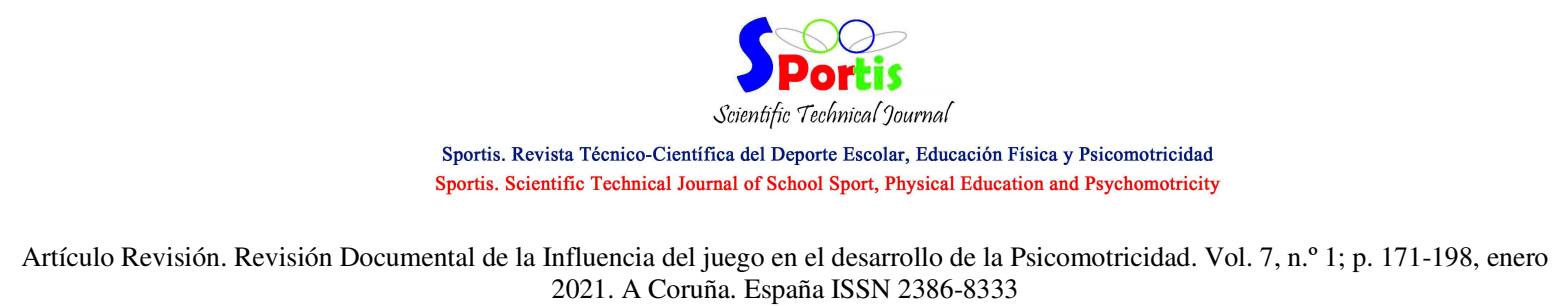
2021. A Coruña. España ISSN 2386-8333

\begin{abstract}
Play is an essential aspect in life, especially in the children's ages,even more so when the first links of human motor development are developed.The objective of thisarticle is to carry out a documentarysystematic review where the linkage of the game to the development of psychomotority is evident. The methodology used was systemic documentary review, through search protocols and heuristic phases. The results show that most of the studies carried out are in the initial stage of education,being the game a factor that is constituted as a necessary and essential tool for the development of child Psychomotority.By way of conclusion, play is parameterized as a major element in the progressin motor skills and in children's biological and psychological growth, in addition to contributing to the pedagogical work of teachers and giving the necessary value to playful and bodily learning in a joint way.
\end{abstract}

\title{
Keywords
}

Play; psychomotricity; motor learning; documentary review. 


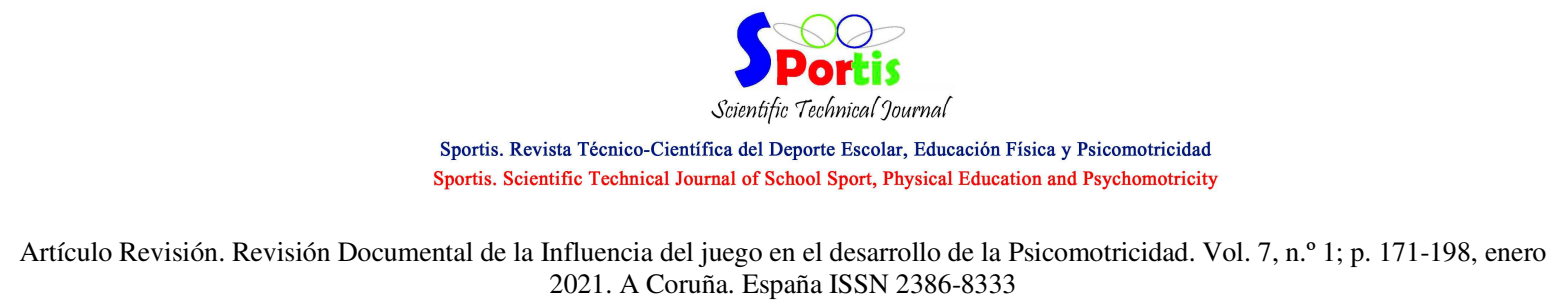
2021. A Coruña. España ISSN 2386-8333

\section{Introducción}

Esta revisión de antecedentes bibliográficos se realiza con el fin de conocer las distintas posturas y actualizaciones conceptuales científicas entorno al juego y su incidencia en el desarrollo de la psicomotricidad. Es necesario partir del concepto de juego, en las edades iniciales, Bonifaz et al. (2019) describen el juego es visto como sinónimo de diversión, en el que se desarrollan otras características como la creatividad; de igual forma, se da sin una normatividad o pautas, pero a medida de que el niño va adquiriendo su desarrollo, el juego se pauta y se va reglamentando. Se comprende que, el juego es una herramienta pedagógica por excelencia, Cáceres et al. (2018) ratifican la idea planteando su vínculo con factores cognitivos, emocionales y más allá de aspectos biológicos; por lo que permite a los niños estar inmerso en sensaciones, y a partir de esta noción construir experiencias.

Por otro lado, el juego en muchas ocasiones se ve como una pérdida de tiempo por lo cual se subestima su función en el quehacer pedagógico, siendo esta una de las mejores etapas para la vida. Pero, como indican Calvo y Gómez (2018) el juego es una acción que se encuentra interiorizada en todos los seres humanos, siendo un comportamiento intrínseco y evidenciado como un patrón de cualquier sociedad, ya que, no existe un humano sin juego.

Desde el punto de vista psicomotriz, el juego potencia el desarrollo del cuerpo y de los sentidos, la fuerza, el control muscular, el equilibrio, la percepción y la confianza en el uso del mismo, se sirven para su desenvolvimiento de las actividades lúdicas (Quirós y Arráez, 2015).

El niño produce movimientos y sensaciones cambiantes al explorarse a sí mismo y a su entorno, cuando descubre una pauta de acción que la repite y ejercita una y otra vez, tanto por experimentar el placer al hacerlo como para comprobar y ampliar sus consecuencias inmediatas y posibilidades de movimiento (Gil et al., 2018).

Ahora bien, en cuanto a psicomotricidad Suasnabas et al. (2019) hacen referencia a sus dos factores: la parte psíquica y motriz, dejando claro que desde el movimiento se hacen connotaciones psicológicas y de expresión del individuo, sus experiencias y su contexto.

Entonces, puede decirse que la psicomotricidad se encarga de llevar a cabo una interpretación Para citar este artículo utilice la siguiente referencia: Andrey Bernate, J. (2021). Revisión Documental de la Influencia del juego en el desarrollo de la Psicomotricidad. Sportis Sci J, 7 (1), 171-198. https://doi.org/10.17979/sportis.2021.7.1.6758 


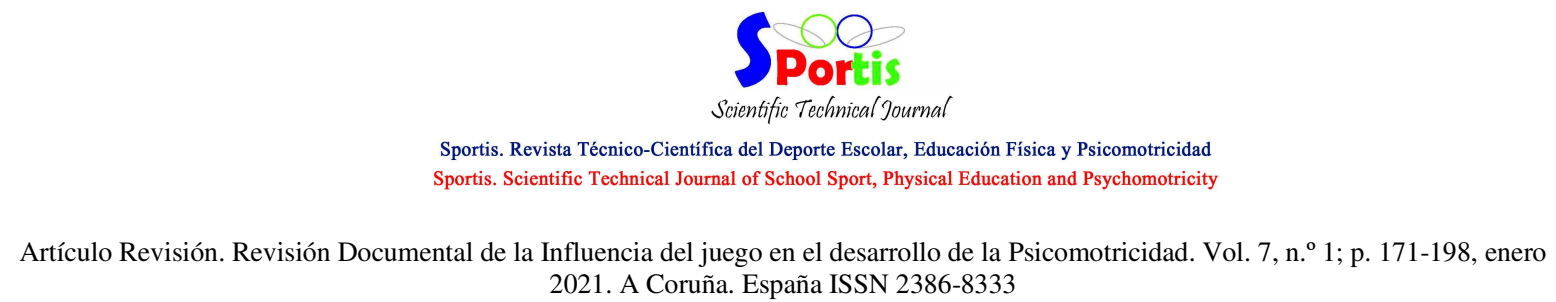
2021. A Coruña. España ISSN 2386-8333

total del ser humano, haciendo posible la interacción corporal y a nivel mental, sin desligar la una de la otra, sino entendiéndose como una sola, es decir, integralidad. Por otro lado, Preciado (2018) menciona que la psicomotricidad se ha visto de diversas formas, pero hasta comienzos del siglo XX ha sido inclinada hacia la psicología y con el paso del tiempo se construye una nueva concepción entorno a la formación integral del ser humano, unido a una corriente pedagógica de formación corporal.

Partiendo de los anteriores conceptos revisados como bases para el análisis conceptual propuesto, se platean distintas concepciones en cuanto a las características esenciales del juego y sus diferentes tipos y como estos se relacionan con el desarrollo de la psicomotricidad infantil. Cuesta et al. (2016) Describen la capacidad del juego cooperativo en el período de educación inicial como un factor fundamental para las clases de educación física bajo el concepto de psicomotricidad, debido a que se va dando un encuentro y conocimiento del cuerpo como génesis de sensaciones, emociones y acciones corporales, y mediante el juego cooperativo en dicha etapa se dan acciones motrices que serán sustanciales como factor de crecimiento de la socialización del niño.

Por otro lado, gracias a los juegos de movimiento de los primeros años, llamados por Henri Wallon funcionales y por Jean Piaget sensorio motores, el niño construye esquemas motores que se ejercita en repetirlos, que se van integrando unos con otros, complejizando y desarrollando el desenvolvimiento de las funciones psicomotrices. Los espontáneos, fomentan una adquisición cada vez mayor de las partes del cuerpo, porque el juego es el medio natural de adquirir experiencias, para la adaptación al ambiente físico y social y para la perfección de los gestos, de forma que sean más seguros, eficaces y coordinados (Méndez, 2015).

Prosiguiendo con el tema, otro caso en el que el juego incide y es una estrategia para el desarrollo de la psicomotricidad es el postulado por Cruz et al. (2020) Donde concluyen que en la escuela se usa el juego de roles, siendo una estrategia usada en la metodología para el aprendizaje que abarca el movimiento y desarrollo psicomotor "poniendo énfasis en la importancia que se pudo demostrar que tiene el juego a la hora de ser utilizado como 


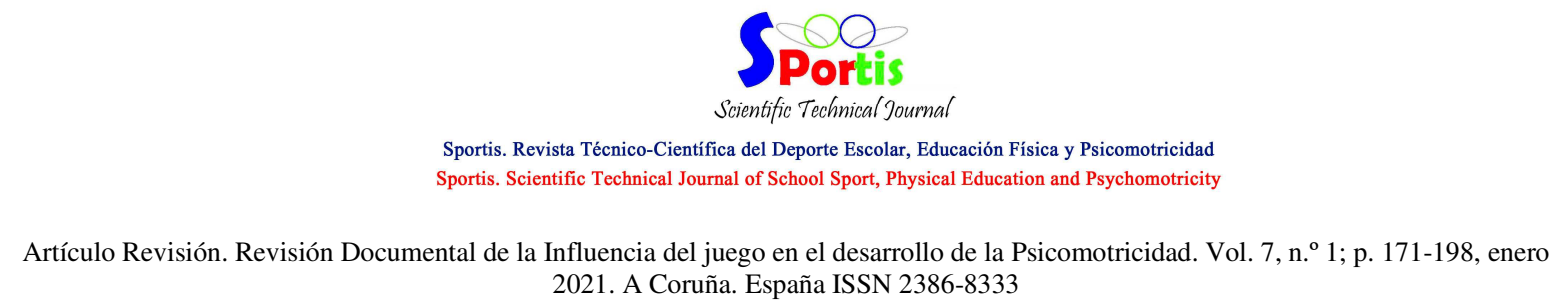
2021. A Coruña. España ISSN 2386-8333

estrategia metodológica para el desarrollo de las habilidades y destrezas motoras gruesas en los infantes" (p.153)

Es oportuno ahora hablar del juego como método terapéutico, y por ende, relacionarlo con el desarrollo psicomotriz; de acuerdo con Serrabona (2020) el juego a nivel educativo y terapéutico es recurrente en aulas de psicomotricidad, en casa el juego tiene repercusiones emocionales, haciendo una clasificación en el tipo de hogares surgidos, ya que, todos los núcleos familiares tienen características diferentes; pero se hace énfasis en las dinámicas familiares de los cuentos clásicos, haciéndolos vivenciados de forma motriz para tratar situaciones y aspectos emocionales más intensos.

De igual forma, el juego y la psicomotricidad tienen el componente rehabilitador, también visto desde el tipo de juego digital, Peñeñory et al. (2018) hacen referencia a que el integrar juegos a través de medios lúdicos tecnológicos, como por ejemplo, los videojuegos, han demostrado el desarrollo de habilidades tanto cognitivas como corporales, estas actividades gamificadas permiten la satisfacción individual diferente al juego tradicional. En el proceso de creación de juegos serios guiados hacia la terapia, es necesario tener presente que las actividades que se realizarán deben engrandecer el aspecto lúdico y motivacional con los elementos formales del juego, esto con el fin de permitir la manifestación de la diversión como elemento clave en dicho proceso a través de los elementos formales de los juegos, permitiendo así la aparición del elemento clave (Rodríguez et al. 2018).

Se puede distinguir que, es de vital importancia también conocer el otro actor fundamental en el proceso educativo: el maestro; en el caso de la educación física como se refieren Martínez et al. (2019) el futuro maestro debe aprender a educar comportamientos motrices, con el fin de conocer y llevar un proceso de mejora en el aprendizaje de la educación emocional para los alumnos. Llevando esta reflexión se plantea que el proceso mecánico motriz se debe dejar en el pasado y dar la bienvenida a la motricidad inteligente. Pero esto solo se hace posible y en su proceso educativo el futuro maestro educado con una formación emocional podrá educar emociones. Teniendo en cuenta dicha base, el juego motor y el juego deportivo son herramientas para que el maestro adquiera dichas competencias, donde ya no se habla de movimiento, sino de conducta motriz (Rebollo, 2015).

Para citar este artículo utilice la siguiente referencia: Andrey Bernate, J. (2021). Revisión Documental de la Influencia del juego en el desarrollo de la Psicomotricidad. Sportis Sci J, 7 (1), 171-198. https://doi.org/10.17979/sportis.2021.7.1.6758 


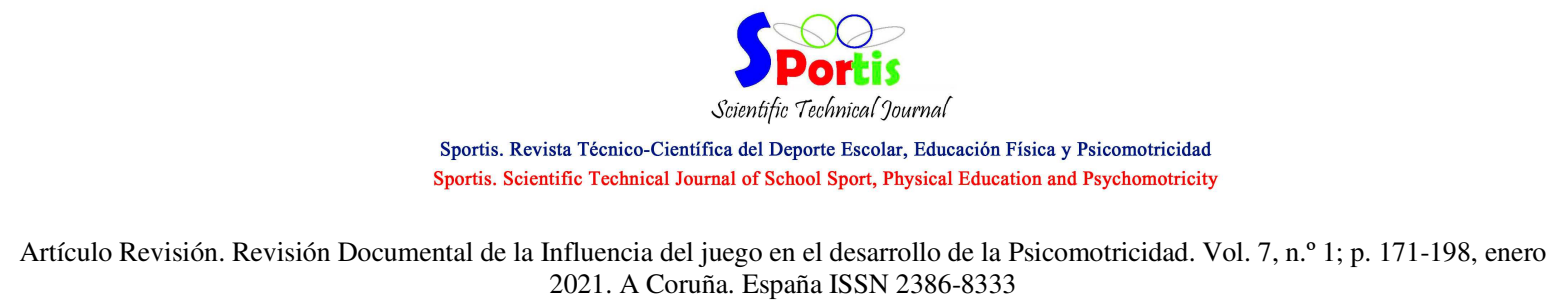
2021. A Coruña. España ISSN 2386-8333

Como es mencionado en un principio, el juego permite la interacción social, repercutiendo directamente en el desarrollo de la psicomotricidad, afirmando dicha concepción Pasihuan (2016) expone que los juegos cooperativos aumentan y potencian la coordinación, dando iniciativa a la interacción social, pues en el estudio hecho se plantea una diferencia significativa antes y después de la aplicación de los juegos para la investigación, esto se sustenta en el desarrollo del lenguaje expresivo corporal y oral.

Retomando la mirada ahora hacia los procesos lógico-matemáticos, es evidente que también tiene incidencia el juego y la psicomotricidad. "El pensamiento es el resultado de un conjunto de operaciones mentales como la observación, la clasificación, el razonamiento; operaciones que todos los niños y niñas están facultados de realizar” (Imbaquingo, 2017 p.46). Por otro lado, relaciona que "las estructuras lógico- matemáticas (asociadas al razonamiento deductivo: desarrollar las capacidades lógicas previas a la comprensión del número) aparecen con los esquemas sensorio-motores, unidos a las acciones de clasificación de seriación como apilar objetos parecidos para hacer torres o murallas" (Imbaquingo, 2017 p. 47).

Para cerrar este apartado es sabido, el juego incide en el desarrollo de la psicomotricidad, aspectos emocionales, sociales, cognitivos y corporales, son algunos de los términos que forman el conjunto denominador de los dos temas abarcados en este artículo, esto con el ánimo de enlazarlos hacia una educación moderna. Es así como, el objetivo de este trabajo es realizar una revisión documental-sistémica donde se evidencie la vinculación hacia el desarrollo de la psicomotricidad infantil por medio del juego.

\section{Método}

La metodología utilizada en esta investigación es cualitativa y su diseño es revisión bibliográfica-sistémica. Hernández y Torres (2018) la consideran como un estudio detallado, selectivo y crítico que integra la información esencial en una perspectiva unitaria y de conjunto, la cual tiene como finalidad examinar la bibliografía publicada y situarla en cierta perspectiva de forma analítica de los referentes conceptuales y epistemológicos. Además se emergen las categorías asociadas en la fase de desarrollo heurístico. Desde lo operativo en correspondencia con la dinámica y estrategia de seguimiento y observación de las diferentes 


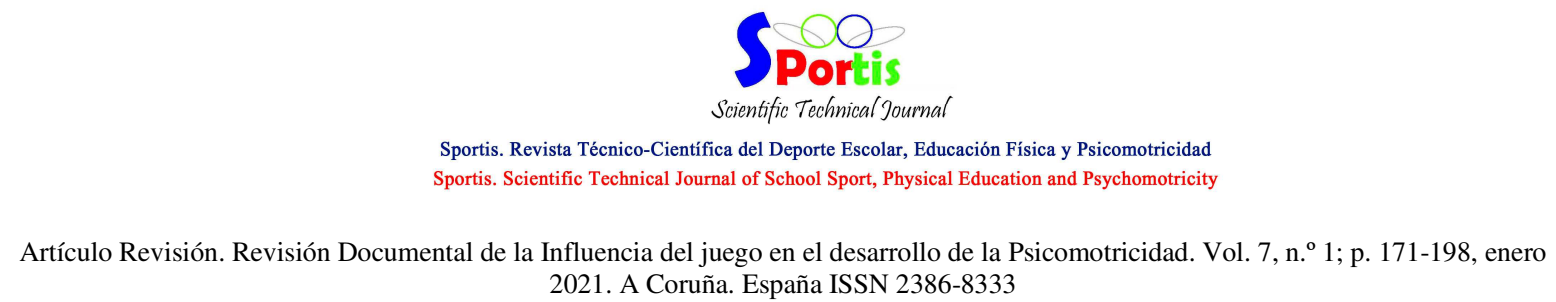

fuentes académicas seleccionadas y su respectiva aplicación. Para el desarrollo de la presente fase se implementó una guía, la cual permite ubicar los pasos y acciones en la matriz categorial y analítica de manera individual; la guía emplea protocolos de búsqueda y revisión de fuentes de información, basados en el modelo categorial propuesto por Betancourt et al. (2020).

El primer protocolo fue estructurado en cinco aspectos: i) el idioma de las fuentes de información; ii) línea de tiempo; iii) palabras clave; iv) artículos relacionados; v) metodología de estudio. Por su parte, el segundo protocolo se estructuró en cuatro elementos:

i) Criterios de revisión; ii) los criterios de exclusión (determinados a partir del problema y los intereses del grupo investigador); iii) los criterios de inclusión representados en los tópicos relevantes a la investigación y iv) la estrategia de extracción de datos. En la tabla 1 se aprecia la guía de fase heurística, mostrando aspectos directos de su aplicación. 


\section{A. Protocolo de búsqueda de fuentes de información}

Tabla 1-Guía de desarrollo fase Heurística

\begin{tabular}{|c|c|c|}
\hline Idioma & & Español \\
\hline $\begin{array}{l}\text { Periodo de } \\
\text { tiempo }\end{array}$ & & $2015-2019$ \\
\hline $\begin{array}{l}\text { Palabras } \\
\text { clave }\end{array}$ & Individual & $\begin{array}{l}\text { Juego, Psicomotricidad, Psicología, aula, terapéutico, educación, } \\
\text { formación, desarrollo, interacción, Motricidad, Individuo, Competencia, } \\
\text { Educación, Acción, Motriz, Corporal, Infancia, Estrategias, Pedagogía, } \\
\text { Física, Didáctica }\end{array}$ \\
\hline & Combinación & $\begin{array}{l}\text { Juego y desarrollo de la psicomotricidad, emociones en Educación Física, } \\
\text { el juego en la clase de Educación Física, desarrollo de la psicomotricidad } \\
\text { en la educación Inicial, Juego e incidencia en el desarrollo del niño } \\
\text { Habilidades psicomotrices }\end{array}$ \\
\hline
\end{tabular}

\begin{tabular}{lll}
\hline $\begin{array}{l}\text { Recursos de } \\
\text { información }\end{array}$ & $\begin{array}{l}\text { i)Bases de datos: Web of Science, Scopus, SportDiscus y Pubmed,; ii) revistas indexadas en } \\
\text { formato digital (educación física); iii) Tesis de maestría y doctorado en repositorios de google } \\
\text { Scholar }\end{array}$ \\
\hline Estrategias & De formación & $\begin{array}{l}\text { Capacitación en uso de bases de datos, en función de la } \\
\text { Investigación. }\end{array}$ \\
\hline & $\begin{array}{l}\text { De generación de } \\
\text { términos }\end{array}$ & $\begin{array}{l}\text { Combinación entre revisión de títulos y resúmenes de artículos en } \\
\text { Bases de datos. }\end{array}$ \\
\hline De búsqueda & $\begin{array}{l}\text { i Búsqueda de términos, restringiendo la búsqueda según } \\
\text { resultados precedentes; ii) búsquedas booleanas (sencillas y por } \\
\text { ecuaciones); iii) consulta a páginas personales de expertos y iv) } \\
\text { Revisión de citaciones y referencias bibliográficas. }\end{array}$ \\
\hline
\end{tabular}

\section{B. Protocolo de revisión de fuentes de información}

Normas de revisión

Explorar la existencia de investigaciones semejantes al tema de estudio, problema de investigación, objetivos y autores. Sucesión de acontecimientos ajustados al contexto. Trabajos publicados en revistas indexadas y revistas científicas especializadas en el área de estudio. Dar lectura al resumen e introducción como estrategia de inclusión o exclusión preliminar (Ver Figura 1).

\section{Criterios de exclusión}

Publicaciones que no están relacionadas con el entorno específico del objeto de estudio. Publicaciones que no se encuentren en revistas científicas, indexadas, bases de datos y referenciadas como productos no investigativos. 


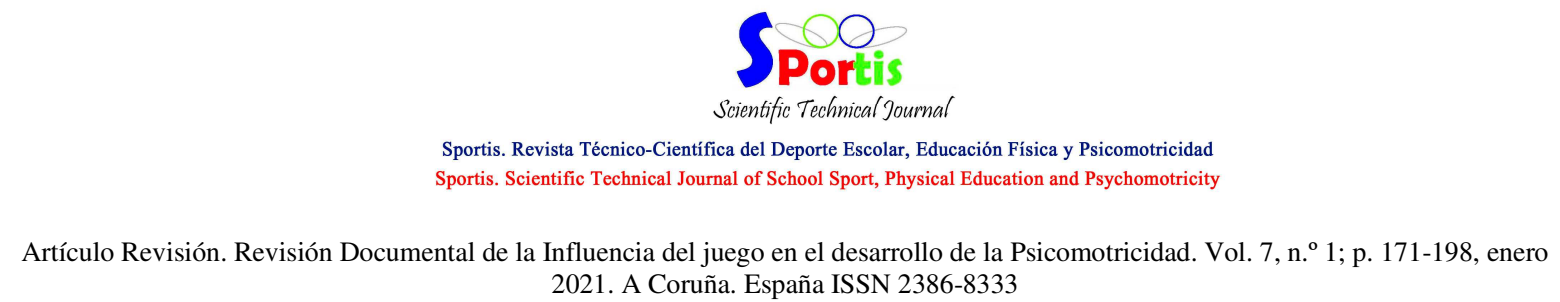

Publicaciones que no se encuentran en la línea y sucesión de acontecimientos plateada para la investigación (Ver Figura 1).

\section{Criterios de inclusión}

Palabras clave ajustadas

Abordaje del diseño de investigación, problema de investigación, metodología, y referentes conceptuales.

Estudios que se encuentran en la línea y sucesión de acontecimientos plateada para la investigación (Ver Figura 1).

\section{Evaluación de hallazgos encontrados}

Para dar cuenta de la aplicación de un protocolo para revisar las fuentes de información, se llevó a cabo una matriz de recolección de datos, en donde se encuentran los criterios de inclusión de la investigación. A continuación, se presenta la estructura del formato de revisión documental, el cual evidencia los tópicos más significativos: título de la publicación, fecha de publicación, autores, medidas u objetivo, diseño, muestra e instrumentos y aportaciones. (Ver tabla 2)

\section{Resultados}

\section{Selección de estudios}

Tras la realización de la búsqueda inicial se obtuvieron 203 resultados. Los documentos fueron analizados y 127 estudios adicionales fueron identificados en las referencias de estos o por otras fuentes, para un total de 303. Además, los artículos duplicados fueron descartados. Esto supuso la exclusión de 14 estudios. De los restantes, 146 fueron retirados después de leer el resumen y 184 fueron determinados para aplicar los criterios de exclusión. Finalmente, tras la realización del análisis, 20 documentos fueron incluidos en esta revisión (ver Figura 1) 


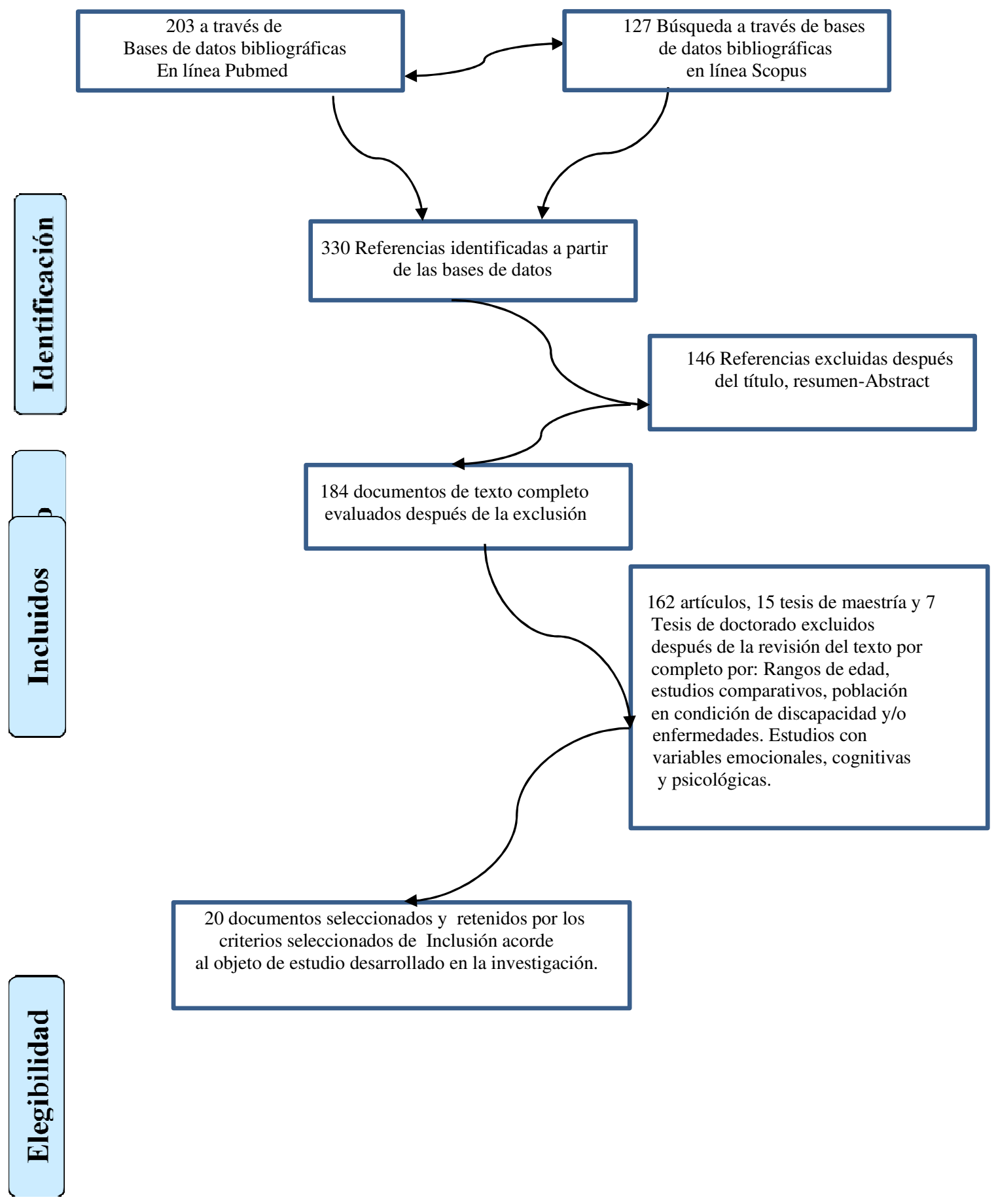

Figura n. ${ }^{0}$ 1. Diagrama de flujo

Para citar este artículo utilice la siguiente referencia: Andrey Bernate, J. (2021). Revisión Documental de la Influencia del juego en el desarrollo de la Psicomotricidad. Sportis Sci J, 7 (1), 171-198. https://doi.org/10.17979/sportis.2021.7.1.6758

http://revistas.udc.es/ 
Tabla 2- Matriz Analítica de Revisión Documental $\underline{\text { Autor/Titulo }}$

Medidas/objetivo

Diseño

Revisión

\section{Muestra/instrumentos $\underline{\text { Aportaciones }}$}

Revisión bibliográfica Los resultados

\begin{tabular}{llrlr}
\hline Vega (2017) & Juegos & Exploró como el \\
recreativos & y & su & juego y el deporte \\
incidencia & en & el & adaptador se \\
desarrollo & psicomotriz & constituye como \\
en los niños con & una herramienta \\
Síndrome de Down del & para los niños con \\
Centro & Educativo &
\end{tabular}

Esperanza

\begin{tabular}{ll}
\hline Jiménez (2019) & Demostrar si con \\
Programa "Juegos & el programa \\
motrices" para & juegos motrices \\
mejorar la & de la institución \\
psicomotricidad en & mejora la \\
niños de 5 años de la & psicomotricidad \\
Asociación Cultural & de los niños de 5 \\
Johannes Gutenberg & años \\
en Comas &
\end{tabular}

revelaron una falta de conocimiento en las técnicas $\mathrm{y}$ formas jugadas acorde a la discapacidad citada. El estudio realizado arrojó como resultados que hubo una mejora significativa en la psicomotricidad de los niños de la institución con el programa ejecutado.

\begin{tabular}{|c|c|c|c|c|}
\hline $\begin{array}{l}\text { Alarcón (2019) El } \\
\text { juego y su relación en } \\
\text { la estimulación de la } \\
\text { psicomotricidad gruesa } \\
\text { en niños y niñas de } 4 \\
\text { años del programa no } \\
\text { escolarizado } \\
\text { educación inicial }\end{array}$ & $\begin{array}{lr}\text { En } & \text { la } \\
\text { investigación } & \text { se } \\
\text { determina } & \text { la } \\
\text { relación } & \text { del } \\
\text { juego en } & \text { la } \\
\text { estimulación } & \text { de } \\
\text { la } & \\
\text { psicomotricidad }\end{array}$ & Cuantitativo & $\begin{array}{l}\text {-17 niños y niñas } \\
\text {-Estadístico Taub de } \\
\text { Kendall }\end{array}$ & $\begin{array}{l}\text { Se generó un } \\
\text { enlace entre el } \\
\text { juego y el } \\
\text { equilibrio, siendo } \\
\text { significativo en la } \\
\text { relación de la } \\
\text { psicomotricidad. }\end{array}$ \\
\hline $\begin{array}{l}\text { Asmat et al. (2018) } \\
\text { Aplicación de } \\
\text { programa de juegos } \\
\text { recreativos para el } \\
\text { desarrollo de la } \\
\text { psicomotricidad en } \\
\text { estudiantes de } \\
\text { educación inicial }\end{array}$ & $\begin{array}{lr}\text { Se } & \text { determina } \\
\text { como } & \text { puede } \\
\text { influir } & \text { el } \\
\text { programa } & \text { de } \\
\text { juegos } & \\
\text { recreativos en el } \\
\text { desarrollo } \\
\text { psicomotor en } \\
\text { niños de } 3 \text { años } \\
\text { de la institución } \\
\text { Jorobamba }\end{array}$ & Pre-experimental & $\begin{array}{l}-11 \text { niños y niñas } \\
\text {-Pre test y post test }\end{array}$ & $\begin{array}{l}\text { La alternativa del } \\
\text { juego recreativo } \\
\text { permite } \\
\text { mejora } \\
\text { significativa en la } \\
\text { evolución de los } \\
\text { aspectos: social, } \\
\text { afectivo y motriz } \\
\text { en las etapas } \\
\text { infantiles } \\
\text { biológicas } \\
\text { morfológicas. }\end{array}$ \\
\hline $\begin{array}{l}\text { Alberca (2017) } \\
\text { Influencia de los } \\
\text { juegos psicomotrices } \\
\text { en el desarrollo de la } \\
\text { Lectoescritura de los } \\
\text { niños de } 5 \text { años de la } \\
\text { I.E.I N 204 "Genara } \\
\text { Lituma Portocarrero" }\end{array}$ & $\begin{array}{l}\text { Los juegos } \\
\text { psicomotrices } \\
\text { pueden incidir en } \\
\text { procesos Lecto- } \\
\text { escritores de } \\
\text { niños de } 5 \text { años de } \\
\text { la institución } \\
\text { mencionada }\end{array}$ & Cuantitativo & $\begin{array}{l}\text {-Totalidad de la } \\
\text { población de la } \\
\text { institución } \\
\text {-Muestreo por } \\
\text { conveniencia }\end{array}$ & $\begin{array}{l}\text { El docente } \\
\text { encargado pone en } \\
\text { marcha procesos } \\
\text { psicomotrices que } \\
\text { se traducen en } \\
\text { estrategias para } \\
\text { buenos resultados } \\
\text { de la comprensión }\end{array}$ \\
\hline
\end{tabular}


Tabla 2- Matriz Analítica de Revisión Documental (continuación)

\begin{tabular}{|c|c|c|c|c|}
\hline Autor/Titulo & Medidas/objetivo & Diseño & Muestra/instrumentos & ortaciones \\
\hline $\begin{array}{l}\text { Guevara y Chudan } \\
\text { (2019) Aplicación } \\
\text { de un Programa de } \\
\text { Juegos } \\
\text { Psicomotrices para } \\
\text { desarrollar la } \\
\text { lateralidad en los } \\
\text { Niños de } 5 \text { años de } \\
\text { la Institución } \\
\text { Educativa Inicial } \\
N^{\circ} 431 \text { del Caserío } \\
\text { Lagunas Huanama, } \\
\text { distrito de Salas, } \\
\text { provincia yregión } \\
\text { Lambayeque. }\end{array}$ & $\begin{array}{l}\text { Con base en } \\
\text { entrevistas } \\
\text { realizadas a los } \\
\text { padres de los } \\
\text { alumnos y la } \\
\text { herramienta de } \\
\text { Observación se } \\
\text { implementa un } \\
\text { programa de } \\
\text { juegos } \\
\text { psicomotrices } \\
\text { para el progreso } \\
\text { de la lateralidad }\end{array}$ & Intervención & $\begin{array}{l}\text {-Niños de } 5 \text { años de la } \\
\text { institución } \\
\text {-Entrevistas y } \\
\text { observación directa }\end{array}$ & $\begin{array}{l}\text { Luego de aplicar } \\
\text { el programa, el } \\
\text { aprendizaje que } \\
\text { se logró en el } \\
\text { desarrollo de la } \\
\text { lateralidad se } \\
\text { plasmó en una } \\
\text { categoría de } \\
\text { valoración alta. } \\
\text { Donde, el } \\
\text { porcentaje de } \\
\text { desarrollo fue del } \\
72 \% \text { con respecto } \\
\text { al nivel inicial. }\end{array}$ \\
\hline $\begin{array}{l}\text { Gallen (2019) } \\
\text { Propuesta de } \\
\text { intervención en } \\
\text { psicomotricidad en } \\
\text { el segundo ciclo de } \\
\text { Educación Infantil }\end{array}$ & $\begin{array}{l}\text { Partiendo de la } \\
\text { observación se } \\
\text { plantea un } \\
\text { refuerzo físico- } \\
\text { motor y } \\
\text { perceptivo- } \\
\text { motor a través } \\
\text { del juego para } \\
\text { aumentar la } \\
\text { motivación del } \\
\text { alumnado }\end{array}$ & Intervención & $\begin{array}{l}\text {-Registro de } \\
\text { observación } \\
\text {-Lista de control } \\
\text { dicotómica }\end{array}$ & $\begin{array}{l}\text { Se llegó al } \\
\text { resultado con } \\
\text { respecto a la } \\
\text { mejora en los } \\
\text { tópicos } \\
\text { evaluados } \\
\text { referente a la } \\
\text { motivación, } \\
\text { fomentando las } \\
\text { relaciones } \\
\text { interpersonales, } \\
\text { partiendode un } \\
\text { ambiente de } \\
\text { aprendizaje } \\
\text { cooperativo }\end{array}$ \\
\hline $\begin{array}{l}\text { Risco (2018) } \\
\text { Programa "Me } \\
\text { divierto Jugando" } \\
\text { para desarrollar la } \\
\text { psicomotricidad } \\
\text { gruesa en niños y } \\
\text { niñas de cuatro } \\
\text { años de una } \\
\text { Institución } \\
\text { Educativa Pública, } \\
\text { Truiillo }\end{array}$ & $\begin{array}{l}\text { Determinar si el } \\
\text { programa "Me } \\
\text { Divierto } \\
\text { Jugando" es útil } \\
\text { para la } \\
\text { evolución de la } \\
\text { psicomotricidad } \\
\text { gruesa del grupo } \\
\text { de alumnos }\end{array}$ & Experimental & $\begin{array}{l}-87 \text { niños Pre test, test } \\
\text { y post test con } \\
\text { dimensiones cognitiva, } \\
\text { motriz y socio- } \\
\text { emocional }\end{array}$ & $\begin{array}{l}\text { Se concluyó que } \\
\text { en los diferentes } \\
\text { niveles se } \\
\text { obtuvo un nivel } \\
\text { de logro, lo cual } \\
\text { supone un } \\
\text { avance hacia el } \\
\text { desarrollo de la } \\
\text { psicomotricidad } \\
\text { gruesa }\end{array}$ \\
\hline
\end{tabular}


Tabla 2- Matriz Analítica de Revisión Documental (continuación)

\begin{tabular}{|c|c|c|c|c|}
\hline Autor/Titulo & Medidas/objetivo & Diseño & Muestra/instrumentos & ortaciones \\
\hline $\begin{array}{l}\text { Sailema } \quad(2019) \\
\text { Juegos tradicionales } \\
\text { Como estimulador } \\
\text { motriz en niños } \\
\text { con Síndrome de } \\
\text { Down }\end{array}$ & $\begin{array}{l}\text { Por medio del } \\
\text { uso de juegos } \\
\text { tradicionales } \\
\text { ecuatorianos con } \\
\text { contenido motriz } \\
\text { afectivo se } \\
\text { pretende } \\
\text { potenciar } \\
\text { habilidades } \\
\text { motrices, } \\
\text { locomotrices y } \\
\text { no locomotrices } \\
\text { en niños con } \\
\text { Síndrome de } \\
\text { Down }\end{array}$ & Correlacional & $\begin{array}{l}-85 \text { niños entre 5-15 } \\
\text { años con Síndrome de } \\
\text { Down } \\
\text {-Test de Bruininks- } \\
\text { Ozeretzky }\end{array}$ & $\begin{array}{l}\text { Los resultados } \\
\text { mostraron que la } \\
\text { aplicación de } \\
\text { juegos } \\
\text { tradicionales } \\
\text { suscita el } \\
\text { aumento de las } \\
\text { capacidades } \\
\text { motrices } \\
\text { fundamentales y } \\
\text { el intelecto }\end{array}$ \\
\hline $\begin{array}{l}\text { Sanz (2019) El } \\
\text { juego divierte, } \\
\text { forma, socializa y } \\
\text { cura }\end{array}$ & $\begin{array}{l}\text { Analizar el } \\
\text { juego como } \\
\text { terapia y fuente } \\
\text { de evolución de } \\
\text { las capacidades } \\
\text { motoras, } \\
\text { intelectuales } \\
\quad y \\
\text { emocionales }\end{array}$ & Revisión & $\begin{array}{l}\text {-Revisión documental } \\
\text {-Análisis por medio de } \\
\text { ensayo }\end{array}$ & $\begin{array}{l}\text { El análisis } \\
\text { realizado lleva a } \\
\text { la conclusión de } \\
\text { que a través del } \\
\text { juego se dan } \\
\text { procesos de } \\
\text { socialización y } \\
\text { terapia para el } \\
\text { niño, por ende, } \\
\text { es una } \\
\text { herramienta para } \\
\text { el crecimiento } \\
\text { de las } \\
\text { capacidades } \\
\text { emocionales, } \\
\text { intelectuales y } \\
\text { motoras. }\end{array}$ \\
\hline
\end{tabular}


Tabla 2- Matriz Analítica de Revisión Documental (continuación) Medidas/objetivo Diseño Muestra/instrumentos Aportaciones

\begin{tabular}{l} 
Autor/Titulo \\
\hline Penadillo (2017) \\
Los juegos de roles \\
en el desarrollo de \\
la psicomotricidad \\
de los niños y \\
niñas de cuatro \\
años de educación \\
inicial -área \\
personal social de \\
una institución \\
educativa del \\
distrito de \\
Huarmey
\end{tabular}

Precisar si los juegos de roles Pre experimental desarrollan la psicomotricidad en la población asignada para la investigación -25 estudiantes de 4 Los resultados años de educación inicial -Prueba T de Student (Pretest, test y posttest) -18 estudiantes -Test de coordinación visomotora en número de 04 juegos importancia los juegos

psicomotrices en psicomotores el desarrollo de la como factor que coordinación repercute en el visomotora fina $\mathrm{y}$ desarrollo gruesa en los alumnos de 4 y 5 años del nivel inicial $\quad \mathrm{N}^{\circ} \quad 244$

Julia Zúñiga

Murillo de Juli

\section{de Correlacional}

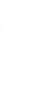

en

Los resultados
de la
investigación
son positivos.
Donde, se
muestra una
mejora

significativa con la utilización de

la estrategia

lúdica, en los

patrones básicos

de movimiento

en los infantes.

Los juegos

psicomotores

son

fundamentales

en el desarrollo

de la capacidad

visomotora fina

y gruesa, por lo

cual se hace la

recomendación

de que el

educador debe

poner en práctica

dicha

herramienta.

\begin{tabular}{ll}
\hline Tolano (2016) & Investigación Cualitativo \\
Evaluación del & sobre el perfil \\
perfil de juego en & del juego de los \\
la clase de & niños \\
psicomotricidad & reafirmando \\
vivenciada en & científicamente \\
niños de educación & el valor de la \\
preescolar & actividad lúdica \\
& y motriz
\end{tabular}

$\begin{array}{ll}\text {-45 alumnos de ambos } & \text { Se ratifica que } \\ \text { sexos de 4-6 años } & \text { las actividades } \\ \text {-Pauta de evaluación } & \text { lúdicas y los } \\ \text { del juego en } & \text { juegos pueden } \\ \text { psicomotricidad } & \text { incidir } \\ & \text { positivamente en } \\ & \text { los niños y en } \\ & \text { cada una de las } \\ & \text { áreas de interés, } \\ & \text { bajo una } \\ & \text { planificación } \\ & \text { adecuada, } \\ & \text { teniendo en } \\ & \text { cuenta que cada } \\ & \text { una tiene } \\ & \text { habilidades y } \\ & \text { aptitudes } \\ & \text { diferentes. }\end{array}$


Tabla 2- Matriz Analítica de Revisión Documental (continuación)

$\frac{\text { Autor/Titulo }}{\text { Rodríguez et a. }}$

(2017) La educación psicomotriz en su contribución al desarrollo del lenguaje en niños que presentan necesidades específicas apoyo educativo

Medidas/objetivo Diseño

Desarrollar un Intervención

programa de

intervención

psicomotriz

basado en el

juego motor,

complementando

la intervención

en logopedia en

niños con

debilidades para

el desarrollo del

habla

Guzmán y Huamaní

(2016) Juegos

tradicionales para el

desarrollo de la

psicomotricidad de

los niños y niñas de

cinco años de edad

en la institución

educativa inicial

San José Obrero de

Pomacanchi

Acomayo - Cusco
Muestra/instrumentos Aportaciones

-1 niñas y 2 niños con Se encontró que edades entre 4-5 años el programa tuvo -Prueba de Desarrollo efectos positivos Batelle (Newborg, en la terapia del Stock y Weck, 2001) lenguaje, así como en la motricidad fina y gruesa del grupo poblacional.
-12 niñas y13 niños -Pretest y post test medida el juego tradicional incide en el desarrollo de la psicomotricidad de la población a estudiar
El emplear los juegos tradicionales genera cambios esenciales en los estudiantes, aumentando un nivel de logro y desempeño en su

psicomotricidad. Además de optimizar el sentido de identidad nacional.

\begin{tabular}{llr}
\hline Chambi y Macedo & Relación & \multicolumn{2}{c}{ entre } \\
(2015) Los juegos & los & juegos Correlacional \\
motores y su relación & motores y el & y \\
con el desarrollo & desarrollo & \\
psicomotriz de los & psicomotriz & que \\
niños de 3 años de la & estimulen & y \\
institución educativa & motiven & la \\
inicial "Alto Jesús" & integralidad \\
del distrito de & motora del niño \\
Paucarpata & \multicolumn{2}{l}{}
\end{tabular}

\begin{tabular}{ll}
\multicolumn{1}{c}{-23 alumnos de 3} & $\begin{array}{l}\text { Los resultados } \\
\text { años }\end{array}$ \\
arrojaron una \\
-Ficha & de clara relación \\
observación & entre los juegos \\
-Test EPP (Escala de & motores y la \\
Evaluación de la & psicomotricidad. \\
Psicomotricidad en & De r igual \\
Preescolar & manera, se \\
& proponen \\
& alternativas para \\
& la formación \\
& integral del niño
\end{tabular}


Tabla 2- Matriz Analítica de Revisión Documental (continuación)

\begin{tabular}{|c|c|c|c|c|}
\hline Autor/Titulo & Medidas/objetivo & Diseño & Muestra/instrumentos & Aportaciones \\
\hline $\begin{array}{lr}\text { Pons y } & \text { Arrufe } \\
(2015) & \text { Análisis } \\
\text { descriptivo de } & \text { las } \\
\text { sesiones } & \text { e } \\
\text { instalaciones } & \text { de } \\
\text { psicomotricidad en } \\
\text { el aula de educación } \\
\text { infantil }\end{array}$ & $\begin{array}{l}\text { La investigación } \\
\text { pretende indagan } \\
\text { el tiempo y los } \\
\text { períodos de las } \\
\text { sesiones } \\
\text { psicomotrices }\end{array}$ & Descriptivo & $\begin{array}{l}\text {-106 alumnos } \\
\text {-Cuestionario Ad } \\
\text { Hoc }\end{array}$ & 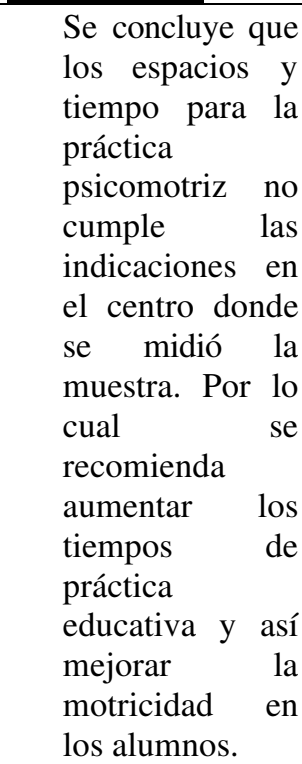 \\
\hline $\begin{array}{l}\text { Vilches y olivera } \\
\text { (2018) El juego } \\
\text { como estrategia para } \\
\text { mejorar el desarrollo } \\
\text { de } \\
\text { psicomotricidad en } \\
\text { niños de } 5 \text { años de } \\
\text { la Institución } \\
\text { Educativa inicial de } \\
\text { Pacchanta, Distrito } \\
\text { de Ocongate- } \\
\text { Quispicanchi-Cusco }\end{array}$ & $\begin{array}{l}\text { Se pretende } \\
\text { determinar la } \\
\text { incidencia del } \\
\text { juego como } \\
\text { estrategia para } \\
\text { en el desarrollo } \\
\text { de la } \\
\text { psicomotricidad }\end{array}$ & Pre experimental & $\begin{array}{l}\text {-21 niños y niñas } \\
\text {-Guía de } \\
\text { observación con } \\
\text { escala de } \\
\text { estimación }\end{array}$ & $\begin{array}{l}\text { Los hallazgos de } \\
\text { la investigación } \\
\text { revelaron que el } \\
\text { juego incide } \\
\text { eficazmente en } \\
\text { el desarrollo } \\
\text { psicomotriz de } \\
\text { los estudiantes; } \\
\text { en el que, luego } \\
\text { del post test el } \\
\text { logro } \\
\text { satisfactorio fue } \\
\text { del } 86 \% \text {. }\end{array}$ \\
\hline
\end{tabular}




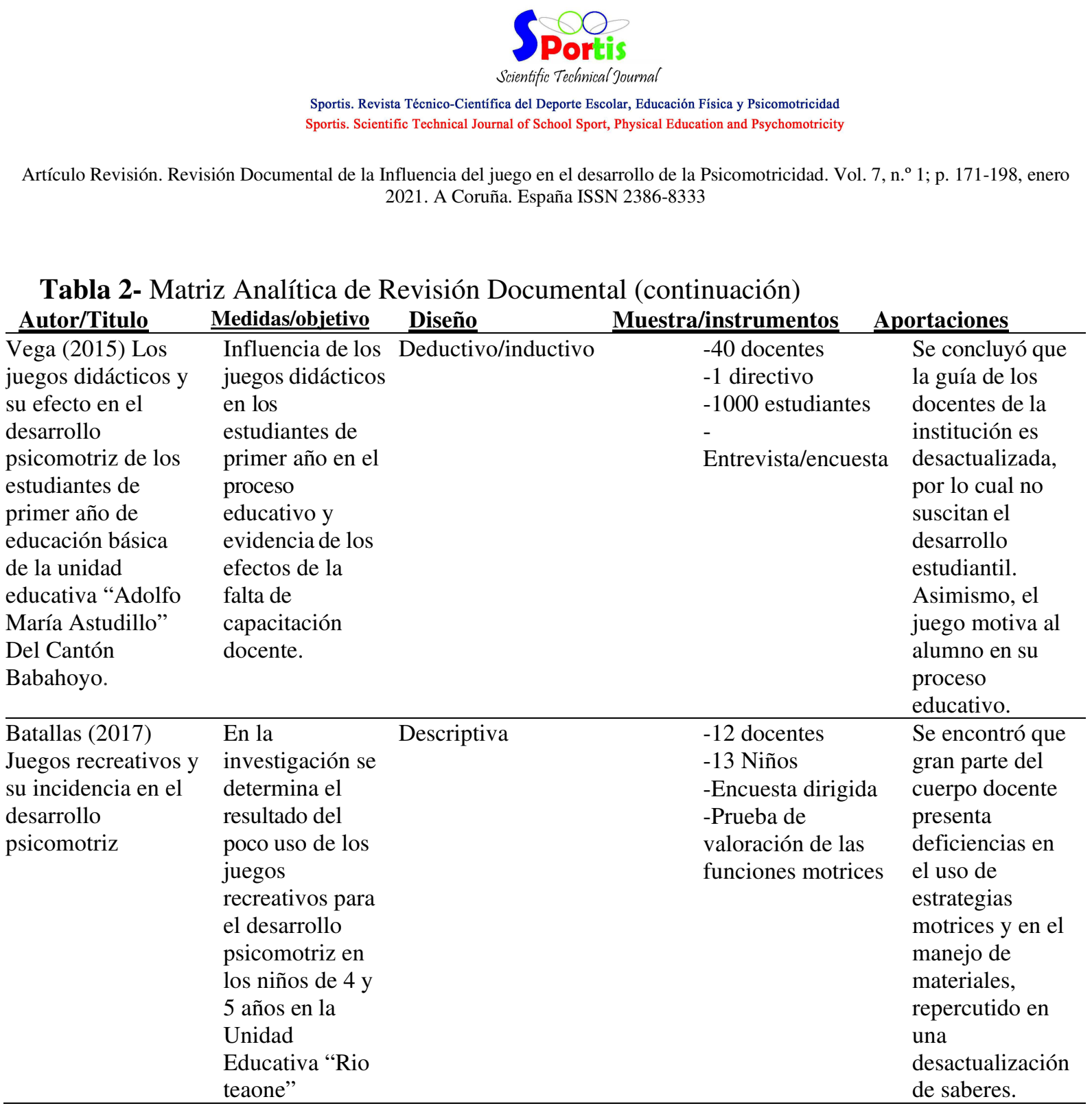

\section{Discusión}

A partir de la revisión documental y la elaboración de la matriz, se presenta el análisis de los artículos y publicaciones científicas de distintos países, en relación al área del juego y su influencia en el desarrollo de la psicomotricidad.

Como se ha mencionado, es claro que el juego tiene gran incidencia en el proceso y desarrollo de la psicomotricidad, siendo uno de los factores y herramientas pedagógicas por excelencia para la formación integral de los niños, en la cual se generan procesos de interrelación y prospección de fortalecimiento en los esquemas corporales de los infantes convirtiendo el juego en una posibilidad de crear una fuerza motriz integradora (Arias y Martínez, 2018; Salazar y Calero, 2019). 


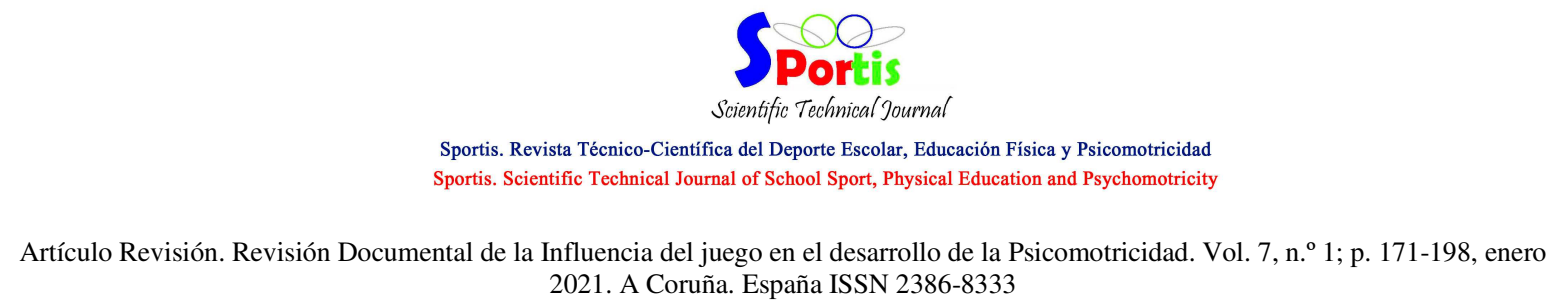
2021. A Coruña. España ISSN 2386-8333

Es evidente que en la gran mayoría los estudios son realizados en la etapa inicial de educación, donde el juego motor es una de las claras fuentes de desarrollo de la psicomotricidad infantil y ello puede justificarse en gran medida a que la capacidad motriz y cognitiva del niño se puede desarrollar de manera más eficiente a través del juego que sin su uso, de igual manera, jugar y aprender se considera como dos aspectos sin distinción, ya que, si el juego presenta retos se tiene una ventana abierta al aprendizaje (Arufe, 2019; Contell, et al. 2017).

De igual modo, el juego en edades tempranas desarrolla y afianza factores que inciden positivamente en la motricidad fina y motricidad gruesa, por lo que se incorporan aspectos como los patrones básicos de movimiento, las capacidades coordinativas y algunos trabajos con respecto a las capacidades condicionales (Arufe, 2019).

Todos estos, son factores que propician el estudio en este campo, las participaciones y evaluaciones psicomotrices por parte de los paneles expertos han venido en una creciente demanda hacia los centros de educación infantil, siendo los mismos docentes del área inicial los que señalan la necesidad de dichas intervenciones (Urrea et al., 2018; Gómez, 2017).

Siguiendo con la línea de la actividad docente para el desarrollo psicomotor. El carácter educativo del juego se pone de manifiesto de forma elocuente en las posibilidades que brinda en la personalidad de educando, lográndose alcanzar altos índices de esfuerzos físicos, las situaciones que se presentan en cada movimiento requieren de soluciones inteligentes para resolver los problemas que en los juegos se plantean y el establecimiento de fuertes relaciones afectivas, coadyuvan a la creación de valores estéticos e intelectuales, desarrolla el trabajo en colectivo, la autodeterminación, la voluntad, el autocontrol, la disciplina, el valor y la perseverancia, al igual les permite una libertad de acción, una naturalidad y un placer que es difícil de encontrar en otras acciones del chico, propicia estados emocionales positivos (Navarro et al., 2017).

Además, el juego podría considerarse una actividad social por excelencia, en la cual pueden verse claramente reflejadas las características del pensamiento, emoción y sentimientos infantiles, toda la actividad humana surge de una necesidad innata de explorar y Para citar este artículo utilice la siguiente referencia: Andrey Bernate, J. (2021). Revisión Documental de la Influencia del juego en el desarrollo de la Psicomotricidad. Sportis Sci J, 7 (1), 171-198. https://doi.org/10.17979/sportis.2021.7.1.6758 


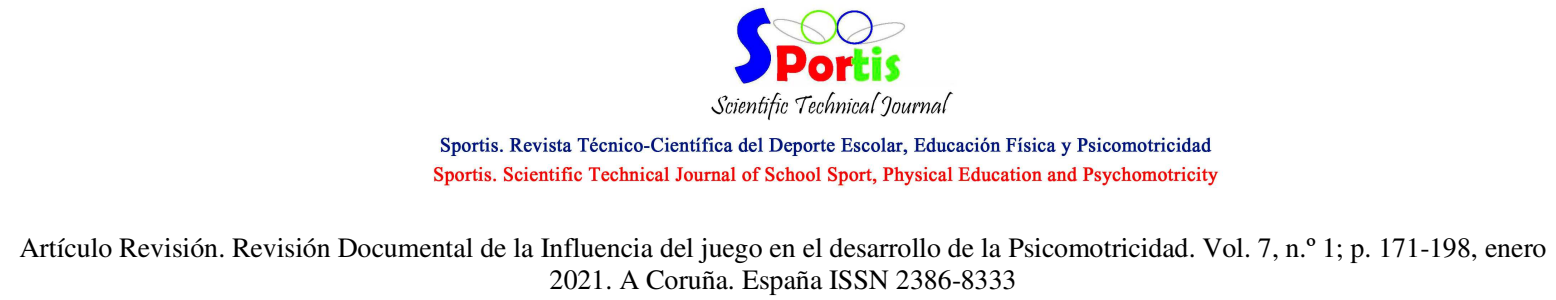
2021. A Coruña. España ISSN 2386-8333

controlar el entorno, aumentando a su vez la motivación y la iniciativa, de tal forma que tanto los bebés como los pequeños, aprenden por medio de la observación y la imitación, normas sociales, etc., que les será posteriormente de gran utilidad en su vida futuro (Camacho y Calvo, 2017)

Lo anteriormente dicho se articula en cierto grado con una de las herramientas de notoria aparición en los hallazgos de esta revisión documental la cual se denomina: los juegos tradicionales, con los que no se usa un material formulado, sino que son los propios alumnos constructores de las herramientas necesarias, que por lo general son sencillas y de fácil acceso (Pérez, 2015; Bernate, et al. 2019). Además, en los aportes revisados se evidencia una estimulación en lo que respecta a motivación y cooperación de los alumnos.

Numerosas comunidades autónomas españolas han venido reconociendo los juegos tradicionales como contenidos necesarios para la clase de Educación Física; por otra parte, en la destreza lingüística su contenido es de alto valor, siendo mecanismo constructor de lenguaje, un claro ejemplo de esto, son los juegos locomotores que involucran saltos acompañados de frases reproducidas al realizar el movimiento. (Hernández y Cañabate, 2020)

En otra instancia, algunos documentos señalan que el juego es de cuestión vital en procesos terapéuticos y fuente de desarrollo de las capacidades motoras, intelectuales y emocionales.

La actividad física y el juego son condiciones estimulantes para los talentos de los niños con Síndrome de Down; estos niños evidencian características escasas, en algunos casos, de su conjunto motor, pero el desarrollar actividades lúdicas permiten su participación activa, lo cual posibilita superar barreras cognitivas, motrices y afectivas. (Garcia, et al. 2018) Del mismo modo, profesionales, no solo del área educativa, sino del campo clínico y de la salud usan el juego con el propósito rehabilitador o terapéutico emocional. Por medio del juego, se ayuda a los niños a contender problemas emocionales y de comportamiento; a través de la expresión y el uso de recursos simbólicos, se permite una carga emocional de experiencias, sentimientos y pensamientos, donde el niño jugando es consciente de su problemática y de allí parte su proceso de sanación. (Bernate et al., 2020; Delgado, et al. 2017)

Para citar este artículo utilice la siguiente referencia: Andrey Bernate, J. (2021). Revisión Documental de la Influencia del juego en el desarrollo de la Psicomotricidad. Sportis Sci J, 7 (1), 171-198. https://doi.org/10.17979/sportis.2021.7.1.6758 


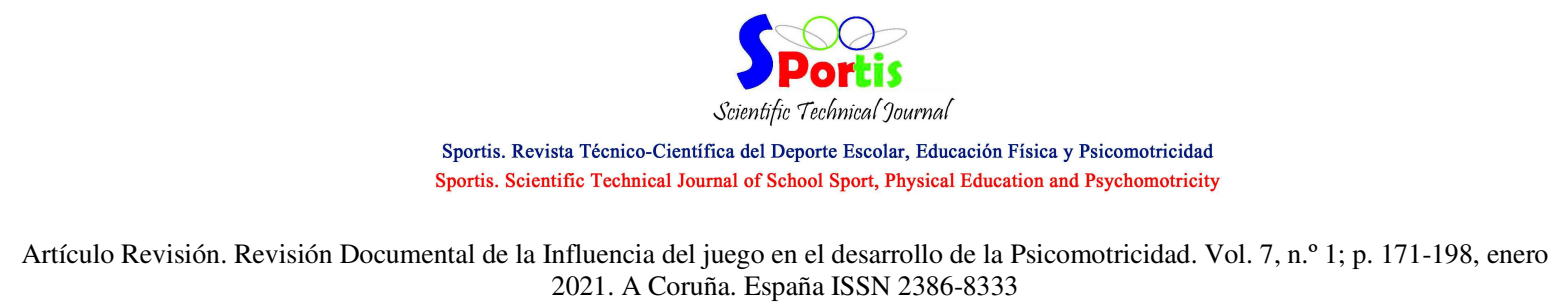
2021. A Coruña. España ISSN 2386-8333

\section{Conclusiones}

El juego en cada una de sus estructuras es una herramienta que permite el crecimiento a nivel cognitivo, emocional y motor de los niños, por lo cual, debe estar presente en cualquier campo pedagógico en el que en sus desempeños esté el desarrollo de la psicomotricidad; haciendo énfasis en edades de educación infantil, donde es necesario beneficiarse de las etapas de desarrollo sensible para usufructuar sus bondades guiado hacia el crecimiento integral del niño.

El juego es imprescindible en la evolución biológica de la población infantil, porque además de desempeñar un papel significativo en el desarrollo físico y psíquico de los niños, constituyen un excelente medio educativo que influye en la formación más diversa y compleja del proceso evolutivo.

Proporcionan el perfeccionamiento de hábitos y capacidades motrices como la rapidez y la resistencia y de cualidades morales como la voluntad, el valor, la perseverancia, la ayuda mutua, la disciplina y el colectivismo.

Es en la etapa de la niñez cuando el desarrollo mental aumenta notablemente y la preocupación dominante es el juego, el niño encuentra en la actividad lúdica un interés inmediato, juega porque el juego es placer, porque justamente responde a las necesidades de su desenvolvimiento integral, en esta fase, cuando el niño al jugar perfecciona sus sentidos y adquiere mayor dominio de su cuerpo, aumenta su poder de expresión y desarrolla su espíritu de observación.

\section{Referencias Bibliográficas}

Alarcón Baldeon, D. (2019). El juego y su relación en la estimulación de la psicomotricidad gruesa en niños y niñas de 4 años del Programa no Escolarizado de Educación Inicial (PRONOEI) Las Rosas, Ayacucho. Repositorio Institucional ULADECH CATOLICA. Disponible en: http://repositorio.uladech.edu.pe/handle/123456789/11534 


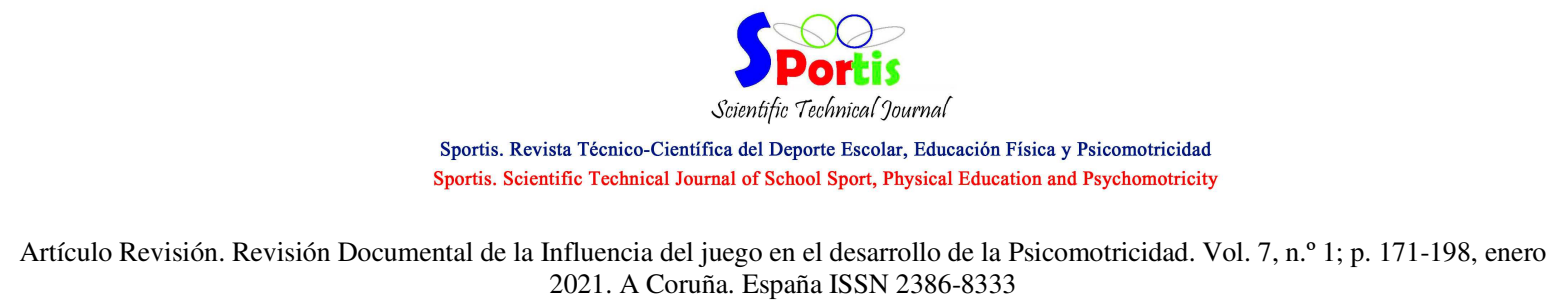
2021. A Coruña. España ISSN 2386-8333

Alberca Surita, Y. (2017). Influencia de los juego psicomotrices en el desarrollo de la lectoescritura de los niños de la I.E.I N 204 "Genara Lituma Portocarrero". Repositorio institucional ULADECH.

Disponible en: http://repositorio.uladech.edu.pe/handle/123456789/2091

Arias, T. G., \& Martínez, C. N. (2018). El juego dirigido en los recreos como método de inclusión del alumnado con necesidades especiales. Sportis. Scientific Journal of School Sport, Physical Education and Psychomotricity, 4(2), 388408. https://doi.org/10.17979/sportis.2018.4.2.3413

Arufe Giráldez, V. (2019). Fortnite EF, un nuevo juego deportivo para el aula de Educación Física. Propuesta de innovación y gamificación basada en el videojuego Fortnite. Sportis. Scientific Journal of School Sport, Physical Education and Psychomotricity, 5(2), 323350. https://doi.org/10.17979/sportis.2019.5.2.5257

Arufe Giráldez, V. (2019). ¿Cómo debe ser el trabajo de Educación Física en Educación Infantil? (¿How should Physical Education work in Early Childhood Education be?). Retos, 37(37), 588-596. https://doi.org/10.47197/retos.v37i37.74177

Asmat Puente, C. E., Huamán Castrillón, L., \& Huancas Montenegro, E. F. (2018). Aplicación de programa de juegos recreativos para el desarrollo de la psicomotricidad en estudiantes de educación inicial. Repositorio Institucional de la Universidad Católica de Trujillo. Disponible en: http://repositorio.uct.edu.pe/handle/123456789/376

Batallas Benavidez, C. V., Cevallos Gorozabel, E. M., \& Angulo Caicedo, A. P. (2017). Juegos recreativos y su incidencia en el desarrollo psicomotriz. Rev. Cuadernos de Educación y Desarrollo. 1(2): 2-18. Disponible en: https://www.eumed.net/rev/atlante/2017/09/juegosdesarrollo-psicomotriz.html

Bernate, J., Fonseca, I., \& Betancourt, M. (2019). Impacto de la actividad física y la práctica deportiva en el contexto social de la educación superior (Impact of physical activity and sports practice in the social context of higher education). Retos, 37(37), 742-747. Recuperado de https://recyt.fecyt.es/index.php/retos/article/view/67875/48883

Para citar este artículo utilice la siguiente referencia: Andrey Bernate, J. (2021). Revisión Documental de la Influencia del juego en el desarrollo de la Psicomotricidad. Sportis Sci J, 7 (1), 171-198. https://doi.org/10.17979/sportis.2021.7.1.6758 http://revistas.udc.es/ 


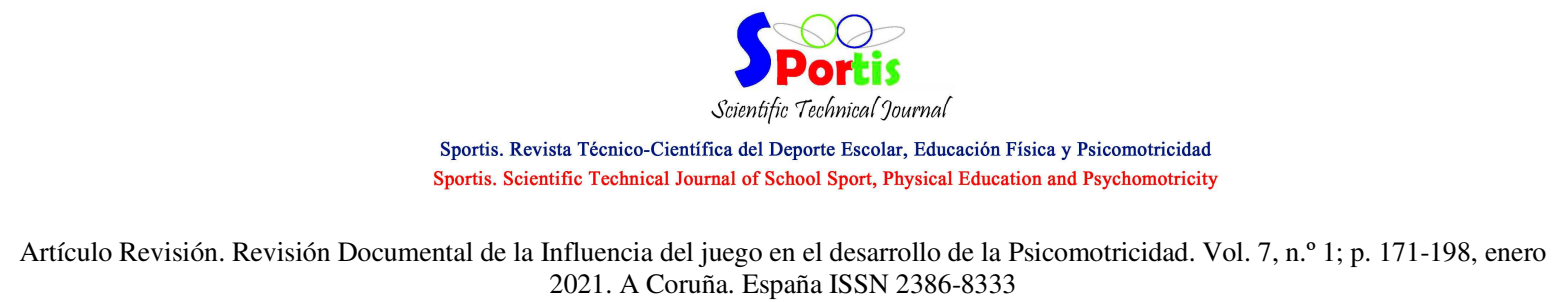
2021. A Coruña. España ISSN 2386-8333

Bernate, J., Guataquira, A., Rodríguez, J., Fonseca, I., Rodríguez, M., \& Betancourt, M. (2020). Impacto académico y profesional de un programa de educación física a nivel universitario (Academic and professional impact of university physical education program). Retos, (39), 509-515. https://doi.org/10.47197/retos.v0i39.81087

Betancourt, M., Bernate, J., Fonseca, I., \& Rodríguez, L. (2020). Revisión documental de estrategias pedagógicas utilizadas en el área de la educación física, para fortalecer las competencias ciudadanas (Documentary review of pedagogical strategies used in the area of physical education to strengthen citizen competenci. Retos, 38(38), 845-851. Recuperado de https://recyt.fecyt.es/index.php/retos/article/view/74918

Bonifaz Arias, I., Chávez Hernández, J., Trujillo Chávez, H., Sánchez Anilema, J., Palacios Valdiviezo, D., \& Álvarez Zambonino, E. (2019). Estaciones motrices físico-educativas para niños y adolescentes con necesidades asociadas o no a discapacidades. Revista Cubana de $\begin{array}{lll}\text { Investigaciones } \quad \text { Biomédicas, } & \text { Recuperado }\end{array}$ de http://www.revibiomedica.sld.cu/index.php/ibi/article/view/54

Cáceres Zúñiga, Francisca, Granada Azcárraga, Maribel, \& Pomés Correa, María. (2018). Inclusión y Juego en la Infancia Temprana. Revista latinoamericana de educación inclusiva, 12(1), 181-198. https://dx.doi.org/10.4067/S0718-73782018000100181

Calvo, P., \& Gómez, M. (2018). Aprendizaje y juego a través de la historia. La Razón Histórica. Revista hispanoamericana de Historia de las Ideas, 40 (2) 21-31. Disponible en: https://www.revistalarazonhistorica.com/40-2/

Camacho Lazarraga, P., \& Calvo Lluch, África. (2017). Estrategia de enseñanza sin errores para el aprendizaje de las habilidades deportivas. Una revision sistemática. Sportis. Scientific Journal of School Sport, Physical Education and Psychomotricity, 3(3), 621638. https://doi.org/10.17979/sportis.2017.3.3.2021

Chambi Mayta, F., \& Macedo Soto, N. C. (2015). Los juegos motores y su relación con el desarrollo psicomotriz de los niños de 3 años de la institución educativa inicial "Alto Jesús" del distrito de Paucarpata. Repositorio Institucional Digitan Universidad Nacional de San Agustín de Arequipa. Disponible en: http://repositorio.unsa.edu.pe/handle/UNSA/1943

Para citar este artículo utilice la siguiente referencia: Andrey Bernate, J. (2021). Revisión Documental de la Influencia del juego en el desarrollo de la Psicomotricidad. Sportis Sci J, 7 (1), 171-198. https://doi.org/10.17979/sportis.2021.7.1.6758

http://revistas.udc.es/ 


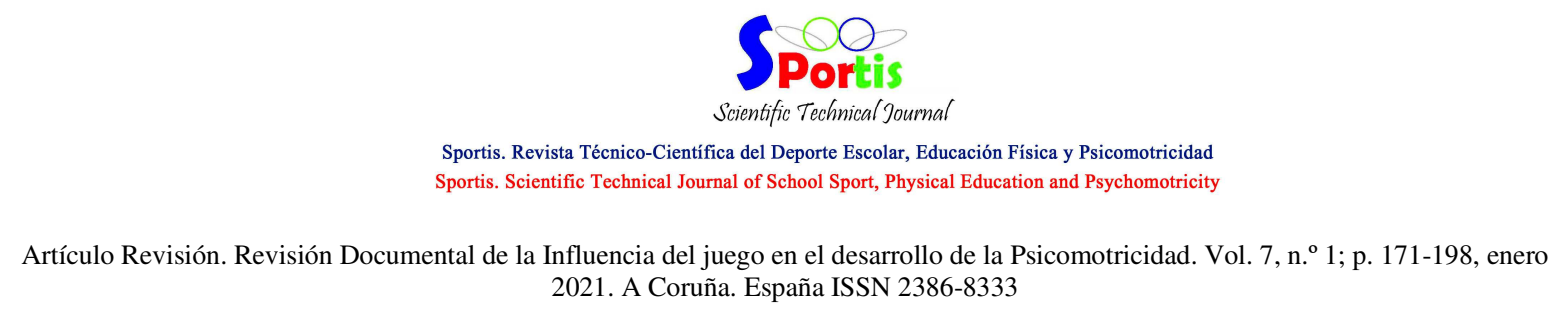
2021. A Coruña. España ISSN 2386-8333

Contell-Lahuerta, S., Molina-García, J., \& Martínez-Bello, V. (2017). Niveles y patrones de actividad física en sesiones de motricidad infantil basadas en el juego libre. Sportis. Scientific Journal of School Sport, Physical Education and Psychomotricity, 3(2), 303322. https://doi.org/10.17979/sportis.2017.3.2.1891

Cruz Gavilanes, T. M., Gavilanes, Y. D. L. N. C., Santander, C. J. M., \& González, M. V. U. (2018). El juego como estrategia metodológica para el desarrollo de la psicomotricidad gruesa en niños de 4 a 5 años. Horizontes de Enfermería. 7 (1): 141-154. Disponible en: https://revistasdigitales.upec.edu.ec/index.php/enfermeria/article/view/162

Cuesta Cañadas, Cristina; Prieto-Ayuso, Alejandro; Gómez Barreto, Isabel María; Barrera, María Ximena; Gil-Madrona, Pedro. (2016). La contribución de los juegos cooperativos a la mejora psicomotriz en niños de Educación Infantil; Repositorio Universitario institucional de recursos abiertos. Disponible en: https://ruidera.uclm.es/xmlui/handle/10578/13797

Delgado-Lobete, L., \& Montes-Montes, R. (2017). Perfil y desarrollo psicomotor de los niños españoles entre 3 y 6 años. Sportis. Scientific Journal of School Sport, Physical Education and Psychomotricity, 3(3), 454-470. https://doi.org/10.17979/sportis.2017.3.3.2002

Gallén Antolli, M. (2019). Propuesta de intervención en psicomotricidad en el segundo ciclo de Educación Infantil. Repositori Universitat Jaume I. Disponible en: http://hdl.handle.net/10234/184003

Garcia Fernández, D. A., Chávez Valenzuela, M. E., Cruz Chávez, C., Guedea Delgado, J. C., Velázquez Saucedo, G., \& Zubiaur González, M. (2018). Impacto de un programa de actividad motriz con funciones ejecutivas fortaleciendo el desarrollo integral del niño. Sportis. Scientific Journal of School Sport, Physical Education and Psychomotricity, 4(1), 3758. https://doi.org/10.17979/sportis.2018.4.1.2060

Gil-Espinosa, F., Romance García, Ángel, \& Nielsen Rodríguez, A. (2018). Juego y actividad física como indicadores de calidad en Educación Infantil (Games and physical activity as indicators of quality in Early Childhood Education). Retos, (34), 252257. https://doi.org/10.47197/retos.v0i34.60391

Para citar este artículo utilice la siguiente referencia: Andrey Bernate, J. (2021). Revisión Documental de la Influencia del juego en el desarrollo de la Psicomotricidad. Sportis Sci J, 7 (1), 171-198. https://doi.org/10.17979/sportis.2021.7.1.6758 http://revistas.udc.es/ 


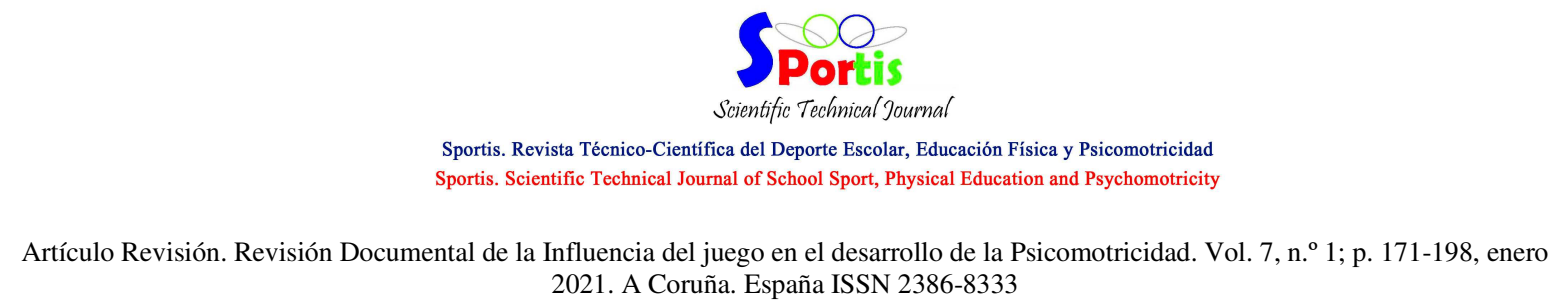
2021. A Coruña. España ISSN 2386-8333

Gómez Smyth, L. (2017). La construcción de instancias de juego con rasgos lúdicos en la educación física del nivel inicial. Sportis. Scientific Journal of School Sport, Physical Education and Psychomotricity, 3(3), 569-588. https://doi.org/10.17979/sportis.2017.3.3.2069

Guevara Acuña, M. F., \& Chudan Rivas, D. M. (2019). Aplicación de un Programa de Juegos Psicomotrices para desarrollar la Lateralidad en los Niños de 5 años de la Institución Educativa Inicial $\mathrm{N}^{\circ} 431$ del Caserío Lagunas Huanama, distrito de Salas, provincia y región Lambayeque. Repositorio Institucional Universidad Nacional Pedro Ruiz Gallo. Disponible en: http://repositorio.unprg.edu.pe/handle/UNPRG/3093

Guzmán Quispe, G., \& Huamaní Champa, M. (2016). Juegos tradicionales para el desarrollo de la psicomotricidad de los niños y niñas de cinco años de edad en la institución educativa inicial San José Obrero de Pomacanchi - Acomayo - Cusco. Repositorio Institucional Digital Universidad Nacional San Agustín de Arequipa. Disponible en: http://repositorio.unsa.edu.pe/handle/UNSA/5614

Hernández-Sampieri, R., \& Torres, C. P. M. (2018). Metodología de la investigación (Vol. 4). México^ $^{\wedge}$ eD. F $\quad$ DF: McGraw-Hill Interamericana. http://64.227.15.180:8080/xmlui/handle/123456789/7

Hernández Gándara, A., \& Cañabate Ortiz, D. (2020). Role-playing y diálogo como protagonistas en la evaluación entre iguales: una experiencia de aprendizaje cooperativo. Sportis. Scientific Journal of School Sport, Physical Education and Psychomotricity, 6(2), 182-203. https://doi.org/10.17979/sportis.2020.6.2.6041

Imbaquingo, P. (2017). El juego psicomotriz en el desarrollo del pensamiento matemático en los niños y niñas de Primer año de Educación General Básica en el Centro Infantil José Luis Román; Repositorio Universidad central del Ecuador. Disponible en: http://www.dspace.uce.edu.ec/bitstream/25000/11598/1/T-UCE-0010-1874.pdf

Jiménez Yánac, Carmen del Pilar. (2019). Programa "Juegos motrices" para mejorar la psicomotricidad en niños de 5 años de la Asociación Cultural Johannes Gutenberg en Comas. Repositorio digital Institucional de la Universidad Cesar Vallejo. Disponible en: https://hdl.handle.net/20.500.12692/30445

Para citar este artículo utilice la siguiente referencia: Andrey Bernate, J. (2021). Revisión Documental de la Influencia del juego en el desarrollo de la Psicomotricidad. Sportis Sci J, 7 (1), 171-198. https://doi.org/10.17979/sportis.2021.7.1.6758 


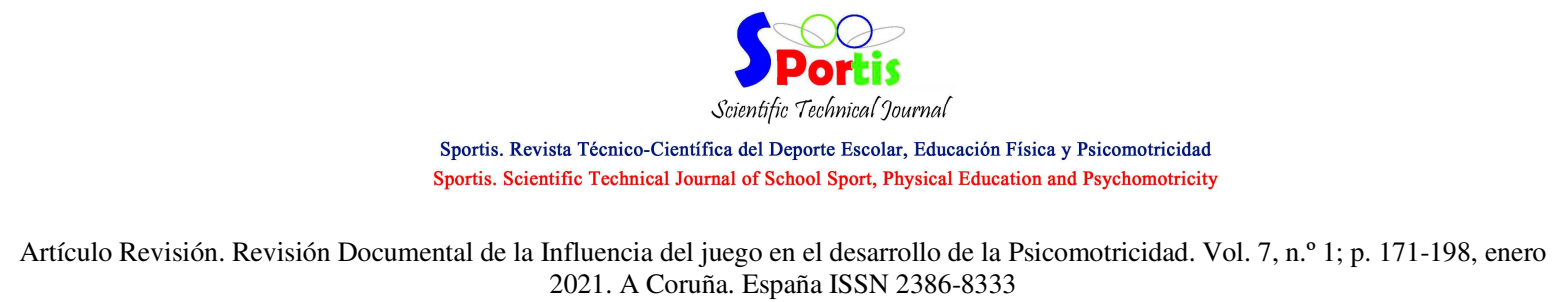
2021. A Coruña. España ISSN 2386-8333

Juli Calderón, D. C. (2019) La importancia de los juegos psicomotores en el desarrollo de la coordinación visomotora fina y gruesa en los alumnos de 4 y 5 años del nivel inicial $\mathrm{N}^{\circ} 244$ Julia Zúñiga Murillo De Juli. Universidad Nacional de Altiplano Vicerrectorado de investigación repositorio institucional. Disponible en: http://repositorio.unap.edu.pe/handle/UNAP/12834

Martínez-Paredes, M. J. M., Vázquez, M. E. C., Alavés-González, V., \& García, M. F. C. (2019). Vivencia emocional del futuro maestro de Educación Física en situaciones psicomotrices con competición. Investigación e Innovación educativa en el Siglo XXI, 9. https://www.researchgate.net/publication/338422526_Vivencia_emocional_del_futuro_ma estro_de_Educacion_Fisica_en_situaciones_psicomotrices_con_competicion

Méndez Giménez, A. (2015). Los juegos deportivos de blanco móvil: Propuesta de categorización e implementación desde un enfoque comprensivo, inclusivo y creativo (The moving target games: A proposal of categorization and implementation from an understanding, inclusive and creative. Retos, (18), 4146. https://doi.org/10.47197/retos.v0i18.34650

Navarro-Patón, R., Basanta-Camiño, S., \& Abelairas Gómez, C. (2017). Los juegos cooperativos: incidencia en la motivación, necesidades psicológicas básicas y disfrute en Educación Primaria. Sportis. Scientific Journal of School Sport, Physical Education and Psychomotricity, 3(3), 589-604. https://doi.org/10.17979/sportis.2017.3.3.2088

Pasihuan Rodríguez, L. R. (2016). Habilidades sociales y juego cooperativo en niños y niñas de 4 años de la institución educativa San José, comas; Repositorio Institucional Universidad César Vallejo. Disponible en: https://hdl.handle.net/20.500.12692/1062

Penadillo Kachahuallpa, D. S. (2017). Los juegos de roles en el desarrollo de la psicomotricidad de los niños y niñas de cuatro años de educación inicial -área personal social de una institución educativa del distrito de Huarmey. Repositorio Institucional ULADECH. Disponible en: http://repositorio.uladech.edu.pe/handle/123456789/13086

Peñeñory, V. M., Bacca, A. F., \& Cano, S. P. (2018). Propuesta metodológica para el diseño de juegos serios para la rehabilitación psicomotriz de niños con discapacidad auditiva.

Para citar este artículo utilice la siguiente referencia: Andrey Bernate, J. (2021). Revisión Documental de la Influencia del juego en el desarrollo de la Psicomotricidad. Sportis Sci J, 7 (1), 171-198. https://doi.org/10.17979/sportis.2021.7.1.6758 


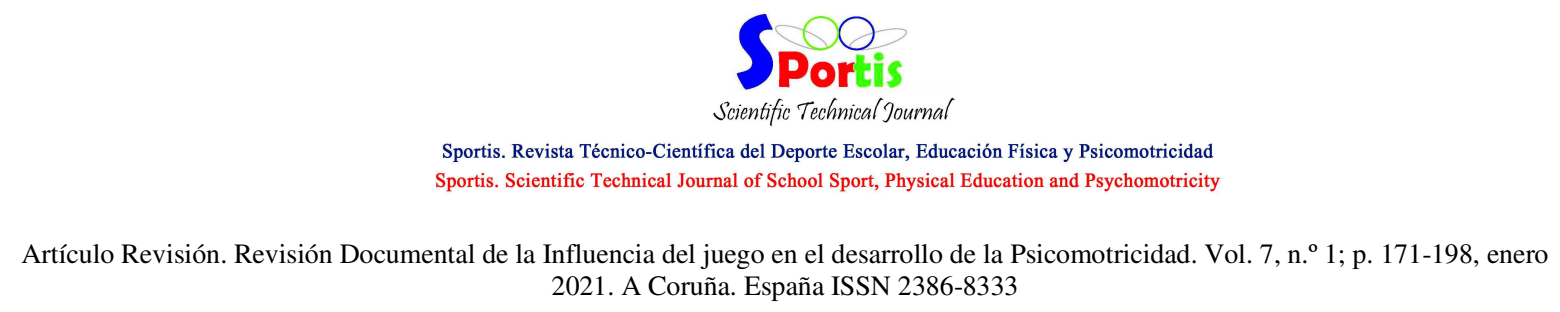
2021. A Coruña. España ISSN 2386-8333

$\begin{array}{llllll}\text { Campus } & \text { Virtuales } & 7 & \text { (2), } & \text { 47-54. } & \text { Disponible }\end{array}$ en: http://www.uajournals.com/ojs/index.php/campusvirtuales/article/view/370

Pérez Chochos, C. R. (2015). Los juegos tradicionales infantiles de persecución y su influencia en el desarrollo de la motricidad gruesa de los niños de 4 años de edad de la Unidad Educativa "Hispano América" del cantón Ambato (Bachelor's thesis, Universidad Técnica de Ambato-Facultad de Ciencias de la Salud-Carrera de Estimulación Temprana). http://repositorio.uta.edu.ec/jspui/handle/123456789/10006

Pons Rodríguez, R., \& Arufe Giráldez, V. (2015). Análisis descriptivo de las sesiones e instalaciones de psicomotricidad en el aula de educación infantil. Sportis. Scientific Journal of School Sport, Physical Education and Psychomotricity, 2(1), 125146. https://doi.org/10.17979/sportis.2016.2.1.1445

Preciado Garcia, M. (2018). La psicomotricidad en la educación preescolar; Repositorio Universidad Nacional de Tumbes. Disponible en: http://repositorio.untumbes.edu.pe/bitstream/handle/UNITUMBES/854/PRECIADO\%20 G\%20ARC\%c3\%8dA\%2c\%20MILUCY\%20GEOVANI.pdf?sequence=1\&isAllowed=y

Quirós Pérez, V., \& Arráez Martínez, J. M. (2015). Juego y psicomotricidad (Primera parte). Retos, (8), 24-31. https://doi.org/10.47197/retos.v0i8.35068

Quirós Pérez, V., \& Arráez Martínez, J. M. (2015). Juego y psicomotricidad. Propuesta y análisis de un programa de trabajo (Segunda parte). Retos, (9), 2331. https://doi.org/10.47197/retos.v0i9.35055

Rebollo González, J. A. (2015). Juegos populares: una propuesta para la escuela. Retos, (3), 31-36. https://doi.org/10.47197/retos.v0i3.35098

Risco Cumpa, L. N. (2018). Programa "Me Divierto Jugando" para desarrollar la psicomotricidad gruesa en niños y niñas de cuatro años de una Institución Educativa Pública, Trujillo. Universidad César Vallejo Repositorio Digital Institucional. Disponible en: https://hdl.handle.net/20.500.12692/26606 


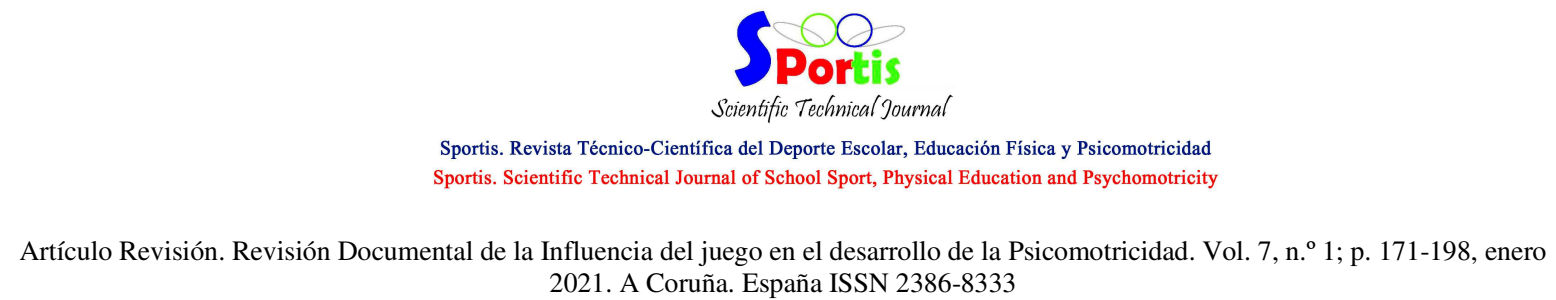
2021. A Coruña. España ISSN 2386-8333

Rodríguez Fernández, J., Oliveira Pereira, B., \& Navarro Patón, R. (2018). Análisis de las prácticas lúdicas y tradicionales en la en la zona norte del Camino Central Portugués y su relación con el ámbito educativo (Analysis of game and traditional practices in the north zone of the Central Portuguese Way and their relation to. Retos, 0(35), 25-30. Recuperado de https://recyt.fecyt.es/index.php/retos/article/view/58857/40394

Rodríguez, $\mathrm{M}^{\mathrm{a}}$ Teresa., Gómez, Isabel Mª , Prieto-Ayuso, Alejandro, \& Gil-Madrona, Pedro (2017). La educación psicomotriz en su contribución al desarrollo del lenguaje en niños que presentan necesidades específicas de apoyo educativo. Revista de Investigación en Logopedia, 7(1), 89-106. [Fecha de Consulta 3 de Julio de 2020]. ISSN: Disponible en: https://www.redalyc.org/articulo.oa?id=3508/350851047005

Sailema Torres, Á., Sailema Torres, M., Amores Guevara, P., Navas Franco, L., Mallqui Quisintuña, V., \& Romero Frómeta, E. (2019). Juegos tradicionales como estimuladores motrices en niños con Síndrome de Down. Revista Cubana de Investigaciones Biomédicas, 36(3). Recuperado de http://www.revibiomedica.sld.cu/index.php/ibi/article/view/72

Salazar Quinatoa, M., \& Calero Morales, S. (2019). Influencia de la actividad física en la motricidad fina y gruesa del adulto mayor femenino. Revista Cubana de Investigaciones Biomédicas, 37(3). Recuperado de http://www.revibiomedica.sld.cu/index.php/ibi/article/view/127

Sanz Cano, Pedro Juan. (2019). El juego divierte, forma, socializa y cura. Pediatría Atención Primaria, 21(83), 307-312. Epub 09 de diciembre de 2019. Recuperado en 04 de julio de 2020 , de http://scielo.isciii.es/scielo.php?script=sci_arttext\&pid=S1139$76322019000300022 \& \operatorname{lng}=$ es\&tlng=es.

Serrabona Mas, J. (2019). Significado y cambio narrativo a través del juego corporal: ¿Qué se juega en el juego de la casa en psicomotricidad? Revista De Psicoterapia, 30(114), 129150. https://doi.org/10.33898/rdp.v30i114.324

Suasnabas Pacheco, S. R., Contreras Delgado, K. L., Schreiber Parra, M. J., \& Suasnabas Pacheco, L. S. (2019). Influencia de la estimulación temprana en el desarrollo psicomotor en los niños y niñas de 1 y 2 años. RECIAMUC, 1(4), 105-127. Recuperado a partir de https://www.reciamuc.com/index.php/RECIAMUC/article/view/166 


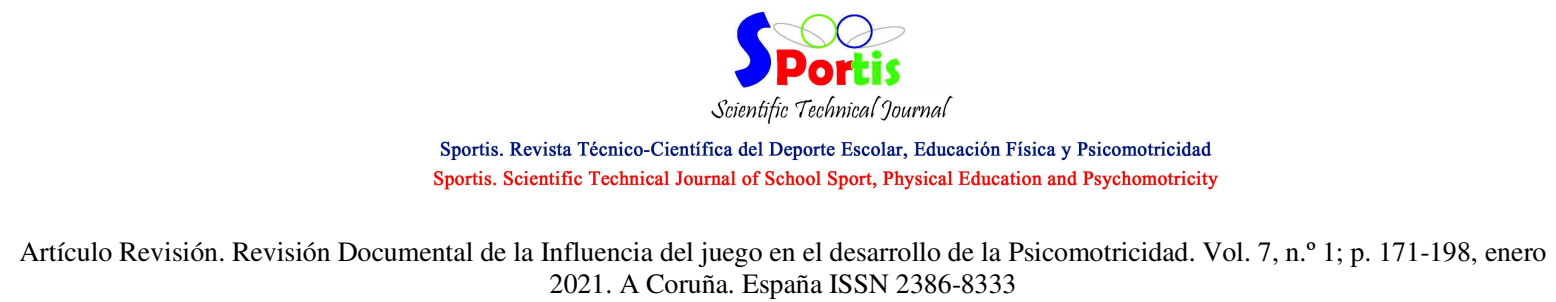
2021. A Coruña. España ISSN 2386-8333

Tolano, E. (2016). Evaluación del perfil de juego en la clase de psicomotricidad vivenciada en niños de educación preescolar. Revista Digital EmásF 43(3): 126-136. Disponible en: https://dialnet.unirioja.es/servlet/articulo?codigo=5758186

Urrea, P., Bernate, J. A., Fonseca, I. y Martínez, A. (2018). Impacto social de los graduados de la Licenciatura en Educación Física, Recreación y Deporte UNIMINUTO. Educación Física y Ciencia, 20 (2), e050. https://doi.org/10.24215/1514-0105e050

Vega, C. M. (2015). Los Juegos Didácticos Y Su Efecto En El Desarrollo Psicomotriz De Los Estudiantes De Primer Año De Educación Básica De La Unidad Educativa "Adolfo María Astudillo" Del Cantón Babahoyo. Repositorio Institucional Universidad Técnica de Babahoyo CEPOS-Centro de Estudios de Posgrados. Disponible en: http://dspace.utb.edu.ec/handle/49000/1765

Vega Landin, Ciro M. (2017). Juegos recreativos y su incidencia en el desarrollo psicomotriz en los niños con síndrome de Down del Centro Educativo Esperanza. Repositorio digital de la UTMATCH. Obtenido de http://repositorio.utmachala.edu.ec/handle/48000/10365

Vilches Canal, L., \& Olivera Ccollatupa, J. (2018). El juego como estrategia para mejorar el desarrollo de la psicomotricidad en niños de 5 años de la Institución Educativa inicial de Pacchanta, Distrito de Ocongate- Quispicanchi-Cusco. Repositorio Institucional Universidad Nacional de San Agustín de Arequipar Disponible en: http://repositorio.unsa.edu.pe/handle/UNSA/5980 